\title{
DIRECT AND REPLACEMENT ION CHROMATOGRAPHY WITH POTENTIOMETRIC DETECTION USING A SILVER/SILVER BROMIDE ELECTRODE
}

\author{
MAREK TROJANOWICZ* and EWA POBOZY \\ Department of Chemistry, University of Warsaw, Pasteura 1, 02-093 Warsaw (Poland) \\ MARK E. MEYERHOFF \\ Department of Chemistry, University of Michigan, Ann Arbor, MI 48109-1055 (U.S.A.) \\ (Received 11th October 1988)
}

\section{SUMMARY}

The use of $\mathrm{Ag} / \mathrm{AgX}$ electrodes as potentiometric detectors in modern ion chromatography methods is re-examined. Contrary to previous reports, in both flow-injection and chromatographic experiments the $\mathrm{Ag} / \mathrm{AgBr}$ electrode is shown to exhibit the greatest sensitivity to the widest range of anions tested. For direct detection in non-suppressed ion chromatography systems, use of the $\mathrm{Ag} / \mathrm{AgBr}$ electrode permits the measurement of separated anions at levels lower than those obtainable by the conventional conductivity method. The $\mathrm{Ag} / \mathrm{AgBr}$ electrode is further shown to be useful as a sensitive detector in replacement ion chromatography. In this case, all anions separated in a suppressed system are quantitatively replaced by bromide before the effluent passes through the electrochemical detector. Cation measurements can also be made by monitoring the exchange of bromide for co-eluting counter hydroxide ions following the replacement stage of the system.

Recent research efforts in modern ion chromatography have focused primarily on the development of more efficient stationary phases and more sensitive methods to detect eluting ions. Among the detectors, apart from conventional conductivity and ultraviolet/visible spectrophotometry, it has been shown that many ions can be conveniently monitored by potentiometry using a variety of very simple indicator electrodes [1]. When the indicating electrode is fabricated with appropriate electroactive materials, including ion-selective membranes, both highly selective and more universal non-selective detectors can be designed.

Among the various indicating electrodes, several workers have already demonstrated the utility of silver-based electrodes of the second kind as detectors in chromatographic systems [2-5]. Similarly, others have adapted solid-state membrane electrodes prepared from sparingly soluble silver salts as chromatographic detectors [6-10]. In either case, the potentiometric response is based 
on a shift in the ionic equilibrium between the electroactive coating or membrane components and analyte anions in the flowing effluent. The magnitude of the observed potential change depends on the stability constant between detected anion and silver ions and on the kinetics of the anion-exchange process occurring at the electrode/flowing solution interface. Both of these factors will also influence the baseline stability of the detector. Extremely low anion detection limits have been reported for ion chromatography systems employing bromide- [6] and iodide-selective [9] solid-state membrane electrodes. Another recent report suggested that the best detection of separated halides and thiocyanate can be achieved with a solid-state sulfide-selective membrane [8].

The aim of this work was to re-examine the utility of simple silver wire electrodes of the second kind as detectors in ion chromatography. The results of a similar study were recently reported by Lockridge et al. [5]. These workers concluded that the best results are obtained with $\mathrm{Ag} / \mathrm{AgCl}$ or $\mathrm{Ag} / \mathrm{AgSCN}$ electrodes (for detection of anions). Data from the present study lead to different conclusions. Indeed, this paper reports on the application of various $\mathrm{Ag} / \mathrm{AgX}$ electrodes as anion detectors both in direct-mode and replacement ion chromatography (RIC) systems. In each case, it will be shown that the $\mathrm{Ag} / \mathrm{AgBr}$ electrode is most useful for such purposes.

\section{EXPERIMENTAL}

\section{Equipment}

The flow-injection system used in preliminary studies to evaluate the anion sensitivities of various $\mathrm{Ag} / \mathrm{AgX}$ electrodes was composed of a Model DP2-2 multichannel peristaltic pump (MLW, Leipzig, G.D.R.), a laboratory-made rotary injection valve with an $80-\mu \mathrm{l}$ sample loop and a flow-through potentiometric detector. A $100-\mathrm{cm}$ length of coiled polypropylene tubing $(0.8 \mathrm{~mm}$ i.d. $)$ was placed between the injector and detector (see below). Potentiometric responses were monitored with a digital $\mathrm{pH} / \mathrm{mV}$ meter (Model N-517, Elwro, Wroctaw, Poland) and recorded on a Model T2-4100 strip-chart recorder (Laboratorni Pristroje, Prague, Czechoslovakia).

The ion chromatography system (Fig. 1) consisted of a Spectra-Physics (San Jose, CA) Model P-8700 solvent-delivery system, a Rheodyne (Cotati, CA) Model 7125 injection valve fitted with a 100- $\mu$ l sample loop and, for comparison studies, a Wescam (Santa Clara, CA) Model 213 conductivity detector. Effluent from the conductivity detector flowed past the $\mathrm{Ag} / \mathrm{AgX}$ potentiometric detector which was connected, together with a downstream saturated calomel reference electrode (SCE), to an Accumet Model $910 \mathrm{pH} / \mathrm{mV}$ meter (Fisher Scientific, Pittsburgh, PA). Analog outputs of both the conductivity and potentiometric detectors were recorded on a Fisher Recordall strip-chart 


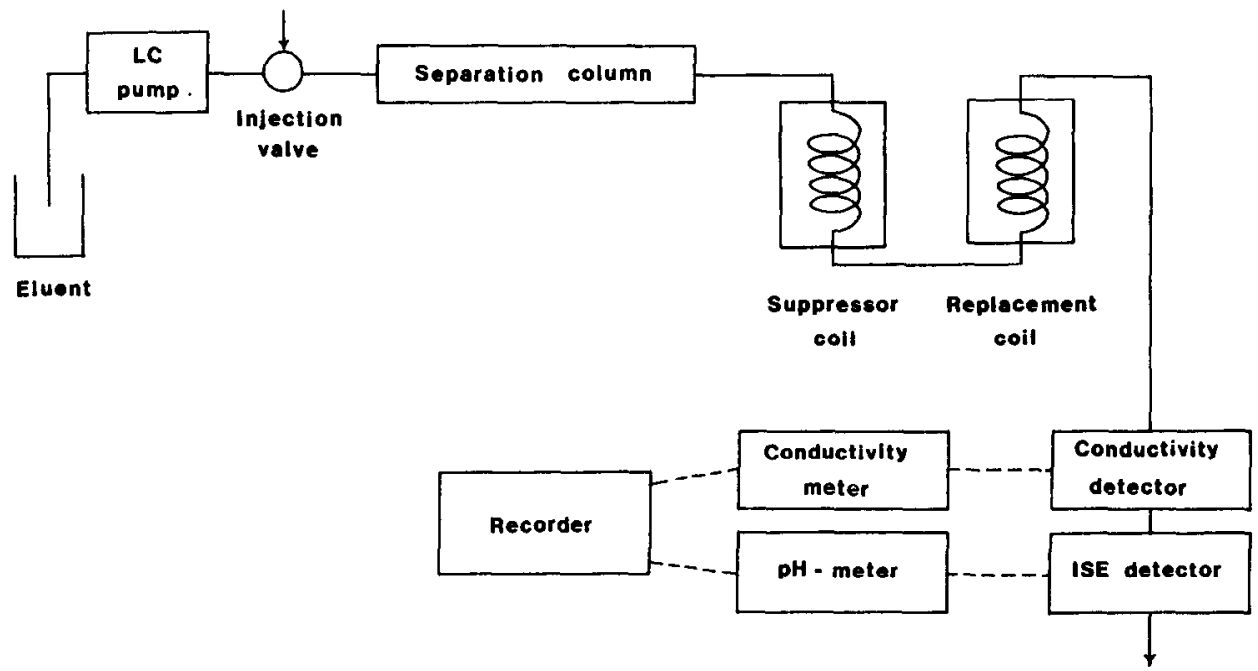

Fig. 1. Schematic diagram of instrumentation used for ion chromatographic measurements.

recorder. For the direct detection mode, the suppressor and replacement ionexchange tubings were removed from the system depicted in Fig. 1.

\section{Columns and ion-exchange tubings}

Anions were separated on a Hamilton (Reno, NV) PRP-X100 column and cations on an Interaction Chemicals (Mountain View, CA) Model ION-210 column. In both cases, an IonGuard polymeric column from Interaction Chemicals was placed between the injection valve and the separation column.

For RIC of anions, a coiled 250-cm length of Nafion 811X tubing (Perma Pure Products, Toms River, NJ) immersed in $12 \mathrm{mM}$ hydrochloric acid was used as the suppressor stage of the system. The replacement stage consisted of a 120-cm length of Raipore T-1030 strong anion-exchange tubing (RAI Research, Hauppauge, NY) immersed in $10 \mathrm{mM}$ potassium bromide solution. In the RIC of cations, a 120-cm length of the Raipore T-1030 tubing immersed in $10 \mathrm{mM} \mathrm{NaOH}$ was used for suppression and a $90-\mathrm{cm}$ length of the same tubing immersed in $10 \mathrm{mM}$ bromide solution served as the replacement stage. Each of the bathing electrolyte solutions was stirred with a magnetic stirring bar.

\section{Potentiometric detector}

The design used for incorporating the $\mathrm{Ag} / \mathrm{AgX}$ electrodes into a flow-through detection unit was the same as that described earlier for detection with metallic copper wires [11]. The $\mathrm{Ag} / \mathrm{AgX}$ indicator electrodes were prepared by anodic deposition of $\mathrm{AgCl}, \mathrm{AgBr}, \mathrm{AgI}$ and $\mathrm{Ag}_{2} \mathrm{~S}$ on the surfaces of pure silver wires $(0.5 \mathrm{~mm}$ o.d., $6 \mathrm{~mm}$ in length) from $0.1 \mathrm{M}$ solutions of the sodium salts of each anion (at $3 \mathrm{~mA}$ for $1 \mathrm{~min}$ ). No special conditioning of the electrodes was re- 
quired before use. Generally, once incorporated as detectors in the flow-through arrangements (i.e., flow injection or chromatography), and prior to injecting any samples, the electrodes were allowed to equilibrate with the flowing carrier electrolyte or mobile phase for 10-15 min to achieve a stable baseline potential.

\section{Reagents}

Analytical-reagent grade chemicals were used. Solutions used in flow-injection experiments were made with triply distilled water (from a quartz still). All solutions used for ion chromatographic measurements were prepared with deionized water obtained from a Milli-Q system (Millipore, Bedford, MA). Sodium perchlorate solution $(10 \mathrm{mM})$, prepared from the solid material (POCh, Gliwice, Poland), was used as the carrier electrolyte in FIA measurements. Eluents used for direct-detection ion chromatography included $2 \mathrm{mM}$ potassium hydrogenphthalate (Aldrich, Milwaukee, WI) adjusted to $\mathrm{pH} 4.0$ with nitric acid and $4 \mathrm{mM}$ sodium 4-hydroxybenzoate, prepared from 4-hydroxybenzoic acid (Aldrich) by adjusting the $\mathrm{pH}$ to 8.6 with sodium hydroxide. For RIC of anions, $15 \mathrm{mM}$ sodium hydroxide solution prepared from the solid material (Aldrich) was employed as the eluent. Cation RIC was carried with 10 $\mathrm{mM}$ nitric acid as the mobile phase.

\section{RESULTS AND DISCUSSION}

\section{Flow-injection measurements}

Flow-injection measurements provide a convenient means of testing the performance of flow-through detectors intended for chromatographic applications. Therefore, in preliminary studies, a direct comparison of the anion sensitivities of several silver electrodes of the second kind was carried out. The response toward twelve different anions was determined in a single-line FIA system using $10 \mathrm{mM}$ sodium perchlorate as the carrier at a flow-rate of $7.8 \mathrm{ml}$ $\min ^{-1}$. All injected sample solutions contained the same level of sodium perchlorate to avoid additional potential changes due to ionic strength differences between the carrier solution and the sample zone. The magnitude of the peak heights obtained for injected anion concentrations of $10 \mu \mathrm{M}$ (corresponding to $0.8 \mathrm{nmol}$ of sample injected) are summarized in Table 1 . With few exceptions, the largest potentiometric responses were obtained with the $\mathrm{Ag} / \mathrm{AgBr}$ electrode. In most cases, the stability of the baseline potential was also superior when the bromide electrode was used. Figure 2 shows typical strip-chart recordings of the FIA system's response to four different anions using the $\mathrm{Ag}$ / $\mathrm{Ag} / \mathrm{Br}$ electrode as a detector. Although not shown, multiple injections $(n=10)$ of a given amount of each anion ( $1 \mathrm{nmol}$ ) yielded fairly reproducible peak heights $(\Delta E)$, with relative standard deviations of $< \pm 2 \%$ for most anions examined. Taking into account the baseline noise level (typically $0.1 \mathrm{mV}$ ), the 


\section{TABLE 1}

Response of anodically coated $\mathrm{Ag} / \mathrm{AgX}$ electrodes to various anionic species in flow-injection measurements

(Carrier, $10 \mathrm{mM} \mathrm{NaClO}_{4}$; amount injected, $0.8 \mathrm{nmol}$ of each species; average peak height for at least two injections)

\begin{tabular}{lllll}
\hline \multirow{2}{*}{$\begin{array}{l}\text { Ion } \\
\text { injected }\end{array}$} & \multicolumn{4}{l}{ Peak height $(\mathrm{mV})$} \\
\cline { 2 - 5 } & $\mathrm{Ag} / \mathrm{AgCl}$ & $\mathrm{Ag} / \mathrm{AgBr}$ & $\mathrm{Ag} / \mathrm{AgI}$ & $\mathrm{Ag} / \mathrm{Ag}_{2} \mathrm{~S}$ \\
\hline $\mathrm{Cl}^{-}$ & 7.2 & 13.4 & 1.5 & 0.0 \\
$\mathrm{Br}^{-}$ & 8.5 & 33.0 & 35.0 & 6.0 \\
$\mathrm{I}^{-}$ & 8.0 & 10.5 & 60.0 & 8.0 \\
& & & & \\
$\mathrm{CN}^{-}$ & 6.7 & 16.2 & 17.7 & 13.3 \\
$\mathrm{SCN}^{-}$ & 8.5 & 22.0 & 6.0 & 5.0 \\
& & & & \\
$\mathrm{~S}^{2-}$ & 7.0 & 20.8 & 20 & 27.0 \\
$\mathrm{SO}_{3}^{2-}$ & 1.8 & 7.0 & 1.2 & 2.2 \\
$\mathrm{~S}_{2} \mathrm{O}_{3}^{2-}$ & 7.0 & 31.0 & 11.0 & 5.5 \\
& & & & \\
$\mathrm{HCO}_{3}^{-}$ & 0.7 & 2.2 & 0.5 & 0.8 \\
$\mathrm{CrO}_{4}^{2-}$ & 0.8 & 2.7 & 0.7 & 0.7 \\
$\mathrm{C}_{2} \mathrm{O}_{4}^{2-}$ & 0.7 & 1.0 & 0 & 0 \\
$\mathrm{PO}_{4}^{3-}$ & 0.6 & 3.2 & 2.0 & 1.2 \\
\hline
\end{tabular}

detection limits for most of the anions listed in Table 1 are well below $1 \mathrm{nmol}$ of sample injected.

For anions toward which the $\mathrm{Ag} / \mathrm{AgBr}$ electrode is least sensitive (e.g., phosphate, chromate), small negative peaks followed the main response peaks. The magnitude of these additional peaks increased with increasing anion concentration. Similar observations were reported previously for measurements with $\mathrm{Ag} / \mathrm{AgCl}$ electrodes [5] and in chromatographic detection with iodide-selective membrane electrodes [9]. Such behavior is consistent with theoretical models proposed to explain the transient response properties of silver halide and other membrane electrodes toward ions for which the membranes exhibit poor selectivity under equilibrium conditions [12-15]. These models suggest that diffusion-controlled differences between bulk solution and surface activities of ions can yield short-term apparent selectivity coefficients that are much larger than the equilibrium selectivity values. Thus, for $\mathrm{Ag} / \mathrm{AgX}$ electrodes, the initial potentiometric response to step changes (either increase or decrease) in the activity of anion $\mathrm{Y}$ (for which the $K_{\mathrm{sp}}$ of $\mathrm{AgY}$ is greater than that of $\mathrm{AgX}$ ) results in a transient potential excursion over several seconds that correlates with the response predicted if the potentiometric selectivity coeffi- 


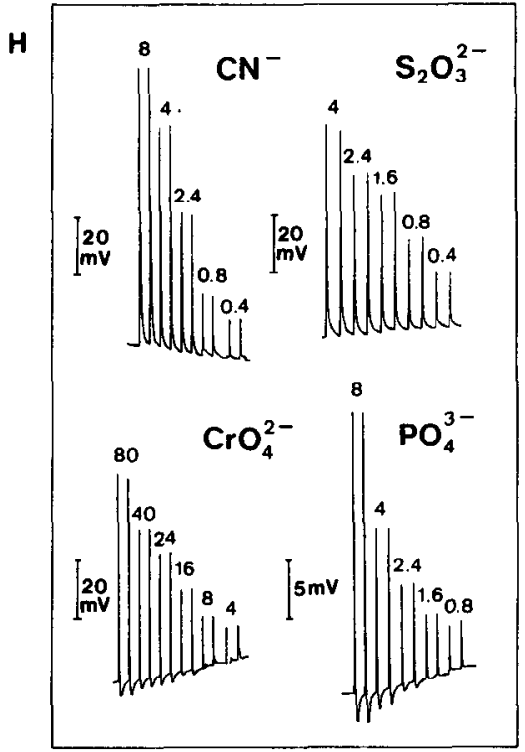

$10 \mathrm{~min}$

Fig. 2. Typical strip-chart recordings for FIA measurements with $\mathrm{Ag} / \mathrm{AgBr}$ electrode at a flowrate of $7.8 \mathrm{ml} \mathrm{min}^{-1}$ using $10 \mathrm{mM}$ sodium perchlorate as carrier solution. Sample volume, $80 \mu \mathrm{l}$. Amounts injected are shown in nmol.

cient were near unity, rather than the theoretical equilibrium value which is equal to $K_{\mathrm{sp}}(\mathrm{AgX}) / K_{\mathrm{sp}}(\mathrm{AgY})$. Consequently, in flow-injection experiments, negative potential transients occur when the sample zone first reaches the detector (taken as the anion response in the above experiments), while a positive potential transient follows owing to a rapid step down (decrease) in the activity of the detected anion $\mathrm{Y}$ as the sample zone leaves the detector.

As described previously for flow-injection measurements using the chloride electrode [16], when detecting the primary ion sensed by the electroactive material (e.g., $\mathrm{Cl}^{-}$for the $\mathrm{Ag} / \mathrm{AgCl}$ electrode) in a small range of potential change from the baseline value, peak heights (in $\mathrm{mV}$ ) are linearly related to concentration injected. As shown in Fig. 3, this study demonstrates that the same relationship is also true for most ions not contained in the electroactive layer covering the Ag electrode (except chromate). At this point, it is not clear why the response to chromate is non-linear in this low response region for each of the $\mathrm{Ag} / \mathrm{AgX}$ electrodes tested. However, the calibration plots presented for phosphate, chromate and cyanide do clearly illustrate the improved anion sensitivity of the bromide electrode relative to other silver electrodes of the second kind. It should be further noted that, as expected, the $\mathrm{Ag} / \mathrm{AgBr}$ electrodes studied exhibited a near Nernstian (logarithmic) response toward bromide $(60.2$ 

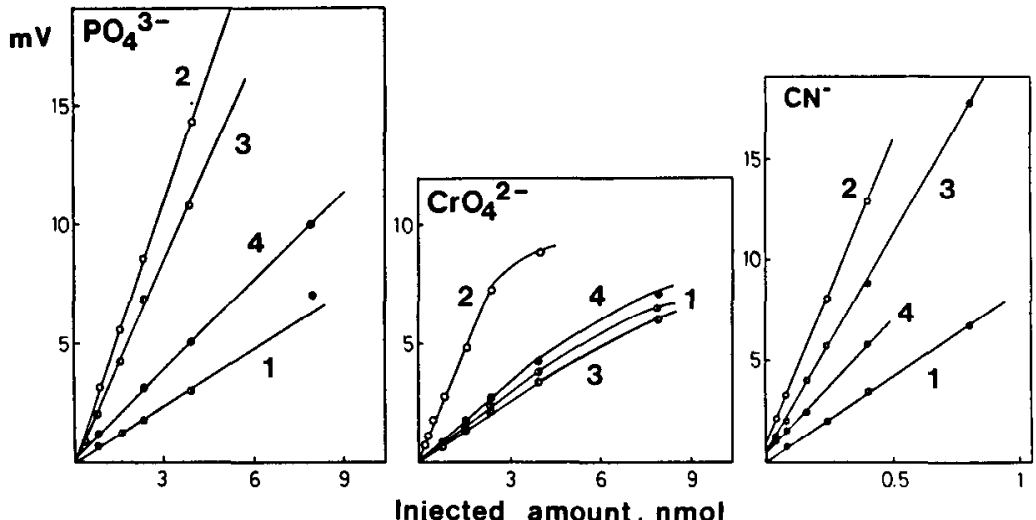

Fig. 3. Calibration graphs obtained for flow-injection measurements with various indicating second kind electrodes: (1) $\mathrm{Ag} / \mathrm{AgCl}$; (2) $\mathrm{Ag} / \mathrm{AgBr}$; (3) $\mathrm{Ag} / \mathrm{AgI}$; (4) $\mathrm{Ag} / \mathrm{Ag}_{2} \mathrm{~S}$. Conditions as in Fig. 2.

$\mathrm{mV}$ decade $\left.{ }^{-1}\right)$ at higher concentrations $\left(10^{-5}-10^{-2} \mathrm{M}\right)$, even under the nonequilibrium flow conditions of these experiments. Hence a linear response to bromide and most of the other ions tested is only observed in concentration ranges yielding relatively small potential changes, i.e., $\Delta E<20 \mathrm{mV}$ ).

\section{Non-suppressed ion chromatography with $\mathrm{Ag} / \mathrm{AgBr}$ electrode}

The use of the bromide electrode for the direct detection of separated anions in single-column chromatography was examined using two different eluents. For a $2 \mathrm{mM}$ phthalate mobile phase at $\mathrm{pH} 4.0$, of the anions investigated by FIA measurements only chloride and bromide exhibited relatively short retention times. Under these conditions, the peaks for chloride and bromide are well separated. Typical chromatograms for such a separation using three different detectors are shown in Fig. 4. When compared with conductivity detection, use of the $\mathrm{Ag} / \mathrm{AgBr}$ electrode offers better simultaneous sensitivity toward chloride and bromide. The potentiometric response toward separated chloride with a $\mathrm{Ag} / \mathrm{AgCl}$ electrode is, however, larger than that observed with the bromide electrode. This is contrary to the FIA results reported above. This discrepancy is probably due to the difference in dynamic conditions between the two experiments (the FIA measurements were performed at a flow-rate four times that used in chromatography).

A more pronounced advantage of using potentiometric detection with the $\mathrm{Ag} / \mathrm{AgBr}$ electrode in comparison with conductivity detection or the $\mathrm{Ag} / \mathrm{AgCl}$ electrode is evident for separations performed with $4 \mathrm{mM}$ sodium 4-hydroxybenzoate ( $\mathrm{pH} \mathrm{8.5)}$ as the eluent (Fig. 5). Under these conditions, the sensitivity towards a separated mixture of chloride, bromide, iodide, thiocyanide and thiosulfate is much better with the $\mathrm{Ag} / \mathrm{AgBr}$ electrode than with either of the 


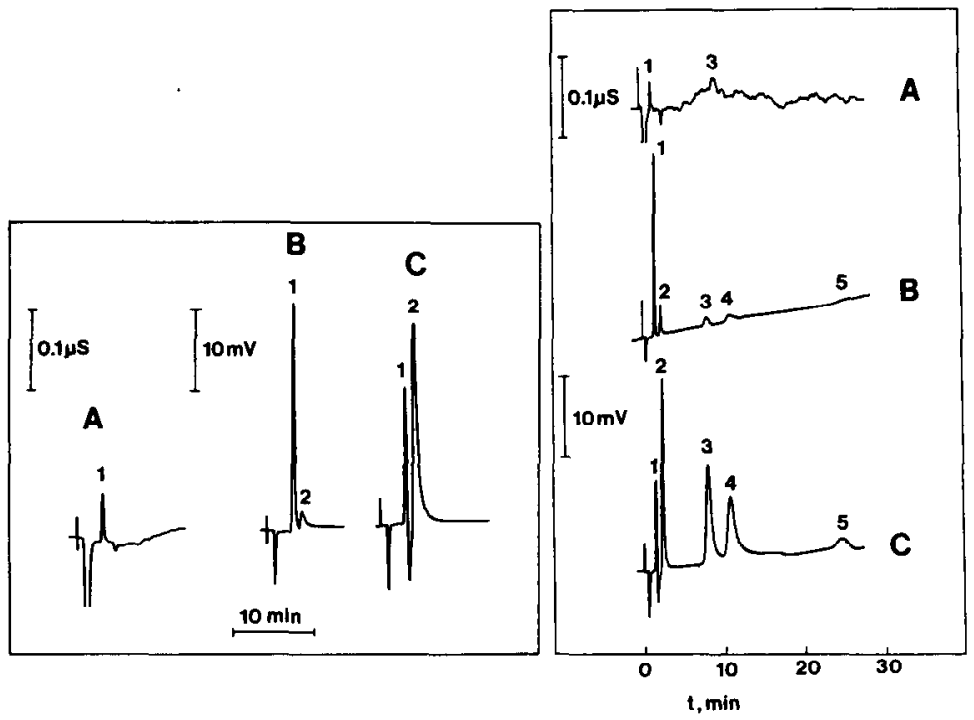

Fig. 4. Chromatograms obtained in single-column system with (A) conductivity detection and potentiometric detection with (B) $\mathrm{Ag} / \mathrm{AgCl}$ and $(\mathrm{C}) \mathrm{Ag} / \mathrm{AgBr}$ electrodes. Eluent, $2 \mathrm{mM}$ potassium phthalate $(\mathrm{pH} 4.0)$ at $2 \mathrm{ml} \mathrm{min}{ }^{-1}$. Injection: $100 \mu \mathrm{l}$ of (1) $0.1 \mathrm{mM} \mathrm{Cl}^{-}$and (2) $0.01 \mathrm{mM}$ $\mathrm{Br}^{-}$.

Fig. 5. Typical chromatograms obtained for single-column system with (A) conductivity detection and potentiometric detection with (B) $\mathrm{Ag} / \mathrm{AgCl}$ and (C) $\mathrm{Ag} / \mathrm{AgBr}$ electrodes. Eluent: $4 \mathrm{mM}$ sodium 4-hydroxybenzoate ( $\mathrm{pH} 8.5$ ) at $2 \mathrm{ml} \mathrm{min}^{-1}$. Injection: $100 \mathrm{ml}$ of (1) $0.1 \mathrm{mM} \mathrm{Cl}^{-}$and 0.01 $\mathrm{mM}(2) \mathrm{Br}^{-}$, (3) $\mathrm{I}^{-}$, (4) $\mathrm{SCN}^{-}$and (5) $\mathrm{S}_{2} \mathrm{O}_{3}^{2-}$.

other two detectors (except for $\mathrm{Cl}^{-}$sensitivity with the $\mathrm{Ag} / \mathrm{AgCl}$ electrode). The detection limits obtained for the five anions with the $\mathrm{Ag} / \mathrm{AgBr}$ electrode are listed in Table $2(S / N=3)$. this evaluation was made by assuming that the recorded peaks in Fig. $5 \mathrm{C}$ are within the linear range of the peak height vs. concentration plots for each of the given anions.

\section{Replacement ion chromatography with $\mathrm{Ag} / \mathrm{AgBr}$ electrode}

The concept of RIC was introduced recently by Hieftje and co-workers [1719]. The method involves use of a suppressed-ion chromatographic system with an additional replacement stage. Within the replacement stage, all separated ions or co-eluting counter ions are exchanged for indicator ions that are sensed downstream by a suitable detector. Whereas in initial studies various spectroscopic detection schemes were used, it has been shown that potentiometric detection with a simple potassium-selective membrane electrode can provide measurement capabilities comparable to those of conventional conductivity and previous RIC detection methods [20]. Given the high sensitivity of the $\mathrm{Ag} / \mathrm{AgBr}$ electrode toward bromide ions, it became of interest to exam- 


\section{TABLE 2}

Detection limits obtained for direct detection in non-suppressed-ion chromatography and for replacement suppressed-ion chromatography using potentiometric detection with $\mathrm{Ag} / \mathrm{AgBr}$ wire electrode

\begin{tabular}{lll}
\hline Measurement mode & Ion detected & $\begin{array}{l}\text { Detection limit } \\
(\mu \mathrm{M})^{\mathrm{a}}\end{array}$ \\
\hline Direct $^{\mathrm{b}}$ & $\mathrm{Cl}^{-}$ & 5.3 \\
& $\mathrm{Br}^{-}$ & 0.25 \\
$\mathrm{I}^{-}$ & 0.47 \\
& $\mathrm{~S}_{2} \mathrm{O}_{3}^{2-}$ & 0.75 \\
$\mathrm{SCN}^{-}$ & 4.3 \\
& & \\
Replacement $^{\mathrm{c}}$ & $\mathrm{F}^{-}$ & 27 \\
& $\mathrm{Cl}^{-}$ & 35 \\
& $\mathrm{Br}^{-}$ & 160 \\
$\mathrm{NO}_{2}^{-}$ & 115 \\
& & \\
Replacement $^{\mathrm{d}}$ & $\mathrm{Li}^{+}$ & 17 \\
& $\mathrm{Na}^{+}$ & 18 \\
& $\mathrm{NH}_{4}^{+}$ & 20 \\
$\mathrm{~K}^{+}$ & 26 \\
\hline
\end{tabular}

${ }^{a}$ Based on $100-\mu \mathrm{l}$ of sample injected. ${ }^{b}$ Eluent, $4 \mathrm{mM}$ sodium 4-hydroxybenzoate ( $\mathrm{pH} 8.5$ ); flowrate, $2 \mathrm{ml} \mathrm{min}^{-1}$. 'Eluent, $15 \mathrm{mM} \mathrm{NaOH}$; flow-rate, $1 \mathrm{ml} \mathrm{min}^{-1}$. Suppressor, 250 -cm Nafion $811 \mathrm{X}$ in $12 \mathrm{mM} \mathrm{HCl}$. Replacement coil, 120 -cm Raipore T-1030 in $10 \mathrm{mM} \mathrm{KBr}$. ${ }^{d}$ Eluent, $10 \mathrm{mM} \mathrm{HNO}$; flow-rate, $0.8 \mathrm{ml} \mathrm{min}^{-1}$. Suppressor, 120 -cm Raipore T-1030 in $10 \mathrm{mM} \mathrm{NaOH}$. Replacement coil, 90-cm Raipore T-1030 in $10 \mathrm{mM} \mathrm{KBr}$.

ine the performance of the $\mathrm{Ag} / \mathrm{AgBr}$ electrode in conjunction with bromide indicator ions as an RIC detection scheme.

Anion chromatography of a mixture containing fluoride, chloride, bromide and nitrite was done using $15 \mathrm{mM}$ sodium hydroxide solution as the eluent and a suppressor stage consisting of a given length of Nafion cation-exchange tubing bathed in $12 \mathrm{mM}$ hydrochloric acid. The replacement stage consisted of an anion-exchange tubing immersed in potassium bromide solution. Typical chromatograms obtained for two different concentrations of a mixture of injected anions are shown in Fig. 6. The detection limits using this approach were poorer than those obtained using the direct detection scheme (see Table 2 ). This poor sensitivity is apparently due to background levels of bromide in effluent originating from continuous replacement of anion impurities in the mobile phase reagents and a constant leak of anions through the walls of the suppressor and replacement tubings. By overcoming these sources of background bromide in the effluent, and by properly minimizing the additional band dispersion in the required length of replacement tubing (i.e., reducing the 


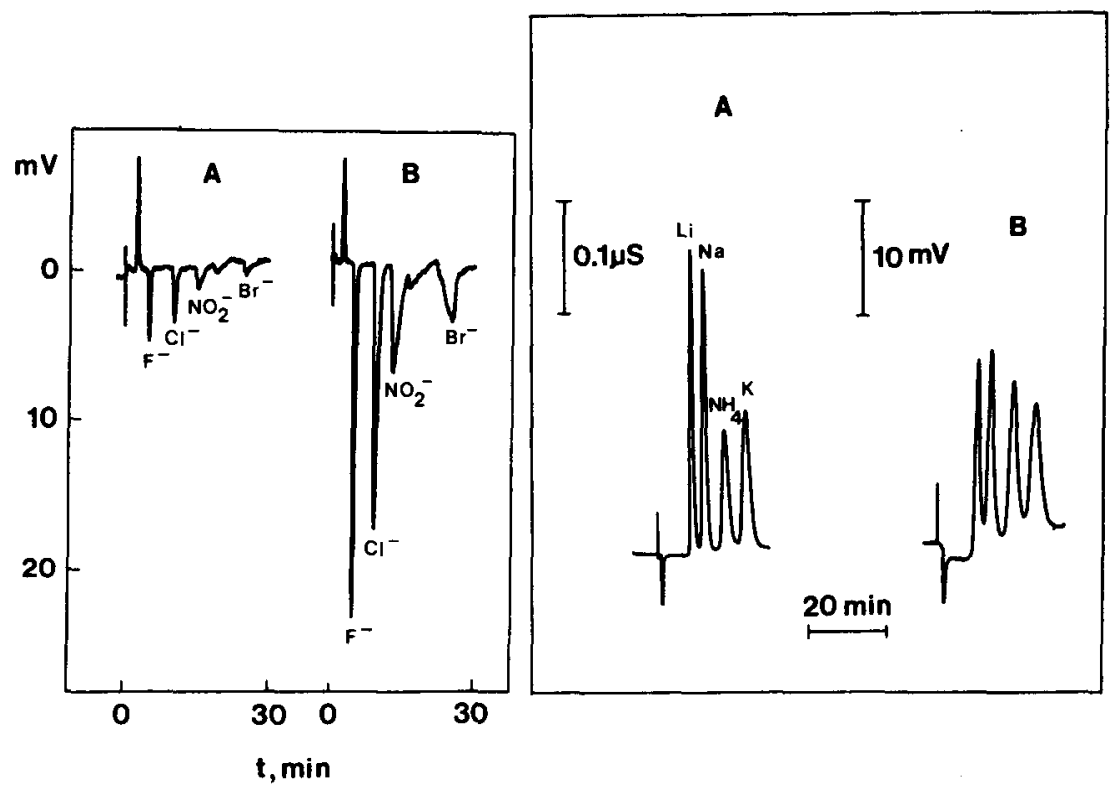

Fig. 6. Anion chromatograms obtained in RIC with potentiometric detection using the $\mathrm{Ag} / \mathrm{AgBr}$ electrode. Eluent: $15 \mathrm{mM} \mathrm{NaOH}$ at $1 \mathrm{ml} \mathrm{min}^{-1} .12 \mathrm{mM} \mathrm{HCl}$ was used as regenerant for the suppressor and $10 \mathrm{mM} \mathrm{KBr}$ for the replacement coil. Injection: $100 \mu \mathrm{l}$ of (A) $0.2 \mathrm{mM}$ and (B) 1.0 $\mathrm{mM}$ of each anion.

Fig. 7. Typical cation chromatograms obtained for (A) suppressed system with conductivity detection and $(\mathrm{B})$ replacement system with potentiometric detection using the $\mathrm{Ag} / \mathrm{AgBr}$ electrode. Eluent: $10 \mathrm{mM} \mathrm{HNO}$ at $0.8 \mathrm{ml} / \mathrm{min} .10 \mathrm{mM} \mathrm{NaOH}$ was used as regenerant for the suppressor and $10 \mathrm{mM} \mathrm{KBr}$ for the replacement coil. Injection: $100 \mu \mathrm{l}$ of a $0.5 \mathrm{mM}$ solution of each cation.

dead volume), significant improvements in RIC detection capabilities should be possible.

One of the principle advantages of the RIC approach is that the same Ag/ $\mathrm{AgBr}$ electrode can also be used as a detector for cation chromatography. In this case, detection is achieved by monitoring the exchange of hydroxide counter ions, co-eluting with the cations after the suppression stage, with bromide ions in the replacement stage. Separation of lithium, ammonium, sodium and potassium ions can be accomplished with $10 \mathrm{mM}$ nitric acid as the mobile phase. Suppression of the acid eluent takes place in an anion-exchange tubing bathed in sodium hydroxide. A typical chromatogram obtained with conductivity detection is shown in Fig. 7A. Addition of another length of anion-exchange tubing immersed in potassium bromide, along with the flow-through $\mathrm{Ag} / \mathrm{AgBr}$ electrode detector, yields the chromatogram shown in Fig. 7B. Estimated detection limits for each of the separated cations using the $\mathrm{Ag} / \mathrm{AgBr}$ electrode in the replacement mode are listed in Table 2. Again, the detectability of each cation is limited by the same sources of background bromide ions in the ef- 
fluent and band broadening in the replacement stage as described above for anion RIC.

\section{Conclusions}

The data reported here regarding the sensitivities of various $\mathrm{Ag} / \mathrm{AgX}$ electrode detectors toward anions in both flow-injection and single-column ion chromatography systems are different to those reported by Lockridge et al. [5]. Although differences in surface morphology originating from variations in the experimental methods used to prepare the electrodes may be the cause of such discrepancies (e.g., the ion-exchange kinetics can vary), for AgX coatings anodically deposited as described here the $\mathrm{Ag} / \mathrm{AgBr}$ electrode appears to be the most useful potentiometric detector for single-column anion chromatography. In addition, it has been shown that the $\mathrm{Ag} / \mathrm{AgBr}$ electrode can also be applied for monitoring cation separations via the use of the RIC approach. In view of the simplicity and versatility of the detector and the accessibility of potentiometric measurement equipment, the $\mathrm{Ag} / \mathrm{AgBr}$ electrode could find wide application in various ion chromatographic procedures.

The authors gratefully acknowledge financial support from Mallinckrodt Sensor Systems.

\section{REFERENCES}

1 M. Trojanowicz, in A. Izaska (Ed.), Proceedings of ElectroFinn Analysis Conference, Turku, Finland, June 1988, Plenum, New York, in press.

2 M.C. Franks and D.J. Pullen, Analyst, 99 (1974) 503.

3 V.V. Bardin, Yu.M. Ivanov and O.F. Shartukov, Zh. Anal. Khim., 33 (1978) 1732.

4 H. Hershcovitz, Ch. Yarnitzky and G. Schmuckler, J. Chromatogr., 252 (1982) 113.

5 J.E. Lockridge, N.E. Fortier, G. Schmuckler and J.S. Fritz, Anal. Chim. Acta, 192 (1987) 41.

6 J. Slanina, F.P. Bakker, P.A.C. Jongejan, L. Van Lamoen and J.J. Mols, Anal. Chim. Acta, 130 (1981) 1.

7 A. Jyo, K. Mori and N. Ishibashi, Bull. Chem. Soc. Jpn., 56 (1983) 3507.

8 H. Muller and R. Scholz, in E. Pungor (Ed.), Ion-Selective Electrodes, 4, American Chemical Society, Washington, DC, 1985, p. 553.

9 E.C.V. Butler and R.M. Gershey, Anal. Chim. Acta, 164 (1984) 153.

10 W. Wang, Y. Chen and M. Wu, Analyst, 109 (1984) 281.

11 P.W. Alexander, M. Trojanowicz and R.P. Haddad, Anal. Lett., 17 (A4) (1984) 309.

12 W.E. Morf, Anal. Lett., 10 (1977) 87.

13 A. Hulanicki and A. Lewenstam, Anal. Chem., 53 (1981) 1401.

14 E. Lindner, K. Toth and E. Pungor, Anal. Chem., 54 (1982) 202.

15 W.E. Morf, Anal. Chem., 55 (1983) 1165.

16 M. Trojanowicz and W. Matuszewski, Anal. Chim. Acta, 151 (1983) 77.

17 S.W. Downey and G.M. Hieftje, Anal. Chim. Acta, 143 (1983) 1.

18 L.J. Galante and G.M. Hieftje, Anal. Chem., 59 (1987) 2293.

19 L.J. Galante and G.M. Hieftje, Anal. Chem., 60 (1988) 995.

20 M. Trojanowicz and M.E. Meyerhoff, Anal. Chim. Acta, 222 (1989) 95. 